\title{
Kekerasan Rumah Tangga dari Persperktif Konseling
}

\author{
${ }^{1}$ Yuda Syahputra, ${ }^{2}$ Stefanus Soejanto Sandjaja, ${ }^{3}$ Hariyani, ${ }^{4}$ Eka Nurlaili \\ ${ }^{1}$ Guidance and Counseling Department, Universitas Indraprasta PGRI, Indonesia. \\ ${ }^{2}$ Psychology, Universitas Kristen Krida Wacana, Jl. Tanjung Duren Raya no. 4, \\ Jakarta Barat Indonesia. \\ ${ }^{3}$ Madrasah Tsanawiyah Negeri 3 Medan, Indonesia. \\ ${ }^{4}$ Guidance and Counseling Department, Universitas Negeri Padang, Indonesia. \\ Correspondence Author, Jl. Nangka No. 58 C (TB. Simatupang), Tanjung Barat, Jagakarsa, \\ RT.5/RW.5, Jakarta Selatan, email ${ }^{1}$ yuda@ konselor.org
}

\begin{abstract}
Abstrack: Tujuan penelitian ini adalah mendeskripsikan kekerasan dalam rumah tangga dari perspektif bimbingan dan konseling dengan menggunakan pendekatan behavior dan kognitif. Penyebab kekerasan dalam rumah tangga adalah sikap dan nilai yang salah tentang peran laki-laki dan perempuan, kekuasaan otoritatif dalam keluarga, ketidaksetaraan gender, status perempuan yang lebih rendah, dan kuasa atas perempuan, serta kepala keluarga yang mengelola atau mengendalikan perilaku semua keluarga yang biasa disebut dengan konsep patriarki. Berdasarkan pemaparan di atas, perlunya pelayanan bimbingan dan konseling untuk mengatasi perilaku kekerasan dalam rumah tangga, yaitu: Adler therapy, rational emotif therapy, cognitive behavioural therapy, dan feminist therapy. Selain itu, pelayanan bimbingan dan konseling dapat menggunakan tiga tahap konseling keluarga menurut Adler yaitu: interview awal, role playing atau bermain peran, dan interpretasi atau penafsiran.
\end{abstract}

Kata kunci: KDRT, Bimbingan dan Konseling, Wanita

\begin{abstract}
The purpose of study is to describe domestic violence from the perspective of guidance and counseling using a behavioral and cognitive approach. Causes of domestic violence are wrong attitudes and values about the roles of men and women, authoritative power in the family, gender inequality, lower status of women, and power over women, and heads of households that manage or control the behavior of all ordinary families called the concept of patriarchy Based on the explanation above, the need for guidance and counseling services to overcome domestic violence behavior, namely: Adler therapy, rational emotive therapy, cognitive behavioral therapy, and feminist therapy. In addition, guidance and counseling services can use three stages of family counseling according to Adler, namely: initial interviews, role playing or role playing, and interpretation or interpretation.
\end{abstract}

Keyword: Domestic Violence, Guidance and Counseling, Women 


\section{PENDAHULUAN}

Kekerasan dalam rumah tangga merupakan fenomena yang mempengaruhi kehidupan jutaan wanita di seluruh dunia (Alhabib, Nur, \& Jones, 2010; Richardson et al., 2002; Riggs, Caulfield, \& Street, 2000; Seegobin, 2002; van der Put, Gubbels, \& Assink, 2019). Lebih dari 10 juta orang Amerika diperkirakan mengalami kekerasan dalam rumah tangga setiap tahunnya (Kessler, Molnar, Feurer, \& Appelbaum, 2001; Schafer, Caetano, \& Clark, 1998; Sorenson, Upchurch, \& Shen, 1996; Stark \& Flitcraft, 1988). Di Australia Barat menunjukkan bahwa kejadian per 100.000 wanita dewasa yang mengalami cidera akibat kekerasan dalam rumah tangga (Ferrante, Morgan, Indermaur, \& Harding, 1996; Hegarty, Hindmarsh, \& Gilles, 2000). Sebanyak 38\% wanita di Curacao telah mengalami beberapa bentuk kekerasan dalam rumah tangga pada suatu saat dalam kehidupan dewasa mereka (van Wijk \& De Bruijn, 2012). Survei Demografi dan Kesehatan Mesir terbaru menemukan bahwa $30 \%$ wanita yang pernah menikah melaporkan beberapa bentuk kekerasan pasangan (Aziz \& El-Gazzar, 2019). Sementara di Indonesia sekitar 24 juta jiwa terutama di pedesaan mengaku pernah mengalami kekerasan yang mayoritasnya adalah kekerasan dalam rumah tangga (Wahab, 2006), selanjutnya tahun 2017 tercatat 348.446 kasus yang dilaporkan (Abdurrachman, 2010; Perempuan, 2017).

Latarbelakang munculnya kekerasan dalam rumah tangga adalah jenis kelamin perempuan, usia muda, pendidikan rendah, dan mengalami viktimisasi kekerasan dalam rumah tangga di masa kanak-kanak (van Wijk \& De Bruijn, 2012). Kehadiran banyak kerabat, mertua, dan anggota keluarga besar lainnya juga disebut-sebut sebagai penyebab potensial kekerasan pasangan intim maupun sebagai faktor pelindung (Clark, Silverman, Shahrouri, Everson-Rose, \& Groce, 2010; Eswaran \& Malhotra, 2009; van Wijk \& De Bruijn, 2012). Kondisi ini selaras dengan penelitian Alizamar, Syahputra, Ardi, \& Trizeta (2018) yang mengungkapkan bahwa laki-laki lebih agresif daripada perempuan, sehingga perempuan lebih cenderung menjadi korban daripada tersangka kekerasan KDRT.

Kekerasan dalam rumah tangga menjadi suatu yang mengerikan bagi hampir setiap perempuan. Dikarenakan kekerasan dalam rumah tangga memiliki konsekuensi signifikan bagi para korban, seperti masalah kesehatan fisik (Boughima, Razine, Benyaich, \& Mrabet, 2018; van der Put, et al., 2019; Walby \& Allen, 2004) dan masalah mental yang serius (Browne, Salomon, \& Bassuk, 1999; Brush, 1989; Bunge \& Locke, 2000; Campbell, 2002; Dillon, Hussain, Loxton, \& Rahman, 2013; Straus, 2017). Bahkan kekerasan dalam rumah tangga juga dapat menghasilkan ketidakstabilan lapangan kerja dengan menghambat prosesproses kerja kognitif seperti self-efficacy dan harapan-harapan kerja (Browne, et al., 1999; Chronister, Harley, Aranda, Barr, \& Luginbuhl, 2012; Chronister \& McWhirter, 2006; Meghan Davidson, Nitzel, Duke, Baker, \& Bovaird, 2012; Showalter, 2016). Kekerasan dalam rumah tangga adalah salah satu masalah kesehatan yang paling mahal dan parah yang dihadapi masyarakat saat ini yang mempengaruhi semua latar belakang budaya, orientasi seksual, usia, etnis, tingkat pendidikan, dan kelas ekonomi sosial (Showalter, 2016)

Rahmawati (2014) Kekerasan dalam rumah tangga (KDRT) merupakan masalah yang hampir dialami di semua negara, kebanyakan KDRT dialami oleh perempuan (Iswari, 2009). Selain itu, KDRT tergolong tindak kejahatan dan pelanggaran berat terhadap nilai-nilai kemanusian (Manan, 2008). Kekerasan dalam rumah tangga sangat beragam bentuknya, baik kekerasan secara fisik, psikis, seksual, dan ekonomi (Astuti, 2011). Rahmawati (2014) dalam kasus KDRT tidak hanya meninggalkan bekas luka fisik, namun juga psikis, karena itu dampak psikis yang ditimbulkan pada anak-anak menjadi perhatian. Tujuan penelitian ini adalah mendeskripsikan kekerasan dalam rumah tangga dan peran bimbingan dan konseling dalam pengentasan masalah KDRT.

\section{METODE}

Jenis penelitian ini adalah penelitian kepustakaan, yaitu serangkaian penelitian yang berkaitan dengan metode pengumpulan data perpustakaan, atau penelitian yang objek penelitiannya dieksplorasi melalui berbagai informasi perpustakaan (buku atau jurnal ilmiah) yang membahas tentang kekerasan dalam rumah tangga. Penelitian perpustakaan atau tinjauan pustaka adalah studi yang secara kritis memeriksa pengetahuan, ide, atau temuan yang terkandung dalam tubuh literatur berorientasi akademik (Syaodih, 2009).

\section{HASIL DAN PEMBAHASAN}




\section{Faktor Penyebab KDRT}

Ada banyak faktor penyebab kekerasan dalam rumah tangg, tetapi yang penting adalah status inferior perempuan di mana nilai dominasi dihargai dan diyakini bahwa laki-laki harus menjadi kepala keluarga, memiliki semua aset keluarga, dan mengendalikan perilaku anggota keluarga mereka (Laeheem \& Boonprakarn, 2017). Penyebab kekerasan dalam rumah tangga adalah sikap dan nilai yang salah tentang peran laki-laki dan perempuan, dan kekuasaan otoritatif dalam keluarga, ketidaksetaraan gender, terutama dalam keluarga di mana suami memiliki otoritas atas istrinya, dan ingin dia setuju dalam semua hal.

Lebih lanjut, faktor yang paling beresiko terhadap kekerasan dalam rumah tangga adalah jenis kelamin perempuan, usia muda, pendidikan rendah, dan mengalami viktimisasi kekerasan dalam rumah tangga di masa kanak-kanak (van Wijk \& De Bruijn, 2012). Kehadiran banyak kerabat, mertua, dan anggota keluarga besar lainnya juga disebut-sebut sebagai penyebab potensial kekerasan pasangan intim maupun sebagai faktor pelindung (Clark, Silverman, Shahrouri, Everson-Rose, \& Groce, 2010; Eswaran \& Malhotra, 2009; van Wijk \& De Bruijn, 2012). Selain itu, suami membuat istri bergantung pada suami sehingga keputusan perceraian yang diambil istri akan mempengaruhi anak-anak mereka (wanita yang bercerai tidak disukai oleh masyarakat) dan dia harus hidup sendiri sambil merawat anaknya (Puawongpaet, 1994; Straus, 2001). Kondisi ini sesuai dengan konsep patriarki, status perempuan yang lebih rendah dan kepemimpinan atas perempuan, serta kepala keluarga yang mengelola keluarga atau mengendalikan perilaku semua keluarga anggota.

\section{Dampak dari KDRT}

Kekerasan dalam rumah tangga memiliki konsekuensi signifikan bagi para korban, seperti masalah kesehatan fisik (Boughima, Razine, Benyaich, \& Mrabet, 2018; van der Put, et al., 2019; Walby \& Allen, 2004) dan masalah mental yang serius (Browne, Salomon, \& Bassuk, 1999; Brush, 1989; Bunge \& Locke, 2000; Campbell, 2002; Dillon, Hussain, Loxton, \& Rahman, 2013; Straus, 2017). Bahkan kekerasan dalam rumah tangga juga dapat menghasilkan ketidakstabilan lapangan kerja dengan menghambat proses-proses kerja kognitif seperti self-efficacy dan harapan- harapan kerja (Browne, et al., 1999; Chronister, Harley, Aranda, Barr, \& Luginbuhl, 2012; Chronister \& McWhirter, 2006; Meghan Davidson, Nitzel, Duke, Baker, \& Bovaird, 2012; Showalter, 2016). Kekerasan dalam rumah tangga adalah salah satu masalah kesehatan yang paling mahal dan parah yang dihadapi masyarakat saat ini yang mempengaruhi semua latar belakang budaya, orientasi seksual, usia, etnis, tingkat pendidikan, dan kelas ekonomi sosial (Showalter, 2016). Oktasari, Stevani, \& Siolihatun (2018) ada beberapa dampak yang ditimbulkan, yaitu: 1) dampak fisik, 2) dampak psikis, 3) dampak seksual, 4) dampak sosial, dan 5) dampak ekonomi. Kemudian dampak lain dari KDRT seperti: dampak fisik, dampak psikologis, dampak seksual, dampak ekonomi dan dampak social (Sutrisminah, 2018). Selain itu KDRT Andi Najemi (2015) mengemukakan dampak dari KDRT menimbulkan kesengsaraan atau penderitaan secara fisik, seksual, psikologis, dan/atau penelantaran rumah tangga termasuk ancaman untuk melakukan perbuatan, pemaksaan, atau perampasan kemerdekaan secara melawan hukum dalam lingkup rumah tangga. Kekerasan demi kekerasan yang dialami oleh korban KDRT ternyata meninggalkan dampak traumatik yang sangat berat (Jayanthi, 2009). Stres juga merupakan dampak dari KDRT, tanda-tanda atau gejala-gejala stres di antaranya merasa khawatir, cemas, gelisah, mudah marah, dan lain-lain (Davidson, John, \& Ann, 2006).

\section{Peran Bimbingan dan Konseling}

Muttaqin, Murtadho, \& Umriana (2016) mengemukakan perlunya konseling untuk membantu mengatasi permasalahan KDRT. Hariyani \& Syahputra (2019) menyatakan bahwa perilaku kekerasan dapat dikurangi dengan layanan bimbingan kelompok dengan menggunakan video, sehingga dengan tampilan video/film perilaku baik atau ceramah agama dapat mengurangi perilaku kekerasan dalam rumah tangga. Upaya lain yang di lakukan yaitu memberikan layanan konseling untuk korban KDRT (Oktasari et al., 2018) seperti : 1) memberikan bantuan konseling dengan bekerjasama dengan Psikolog, 2) bekerjasama dalam hal penanganan medis, 3) pendampingan dan bantuan hukum, serta 4) rumah aman yang bentuknya kemitraan (Hartati, 2013). Adanya bimbingan Islam mengenai pernikahan dan pembinaan kehidupan berkeluarga juga bisa 
menjadi upaya pencegahan dari KDRT (Faqih, 2004: 82) yaitu bimbingan dan konseling Islam berstandar kepada kemutlakan kuasa Allah dan kemaksimalan usaha sendiri (Arifin, 2009: 12). Muttaqin et al. (2016) menjelaskan hakikat bimbingan dan konseling Islam untuk membantu individu belajar mengembangkan fitrah atau kembali kepada fitrah, dengan cara memberdayakan iman, akal, dan kemauan yang dikaruniakan Allah. Selain itu, Ada beberapa pendekatan yang dapat dilakukan untuk membantu korban kekerasan dalam rumah tangga, antara lain:

\section{Pendekatan-pendekatan Konseling Keluarga Adler Therapy}

Tujuan pendekatan ini adalah untuk mempermudah perbaikan hubungan anak dan meningkatkan hubungan di dalam keluarga, dengan cara mengajarkan bagaimana menyesuaikan diri yang lebih baik terhadap anggota keluarga dan bagaimana hidup bersama dalam keluarga. Dinkmeyer, Dinkmeyer, \& Sperry (1987) mengungkapkan bahwa tujuan ini adalah menyempurnakan kehidupan dalam keluarga dengan cara sharing atau berbagi dengan sesama anggota keluarga atas dasar prinsip demokrasi dalam menyelesaikan konflik, memperbaiki orientasi yang konstruktif antara anggota keluarga menjadi komunikasi dua arah dan yang lebih utama adalah mengajarkan anggota keluarga agar mampu memberikan semangat dan dorongan untuk berkembang.

Ada tiga tahap konseling keluarga menurut Adler dalam Laela (2015) yaitu: interview awal, role playing atau bermain peran, dan interpretasi atau penafsiran. Intervew awal, pada tahap ini konselor membantu dalam mendiagnosis tujuan anak, mengevaluasi orangtua dalam mendidik anak, memahami iklim keluarga, dan membuat rekomendasi khusus bagi perubahan dalam situasi keluarga tersebut. Proses interview ini difokuskan pada usaha memberikan keberanian dan memperkuat semua anggota keluarga. Anggota keluarga ditanya bagaimana mereka melalui hari-harinya dalam kehidupan keluarga, suatu pandangan tertentu tentang dimulainya kehidupan keluarga untuk berkembang didasarkan pada pola-pola interaksi antara saudara-saudara sekandung dan posisi anakanak didalam keluarga. Orangtua juga ditanya tentang pandangannya mengenai situasi keluarga, misalnya kepedulianya pada anakanak mereka.
Role playing atau bermain peran, tahap kedua ini digunakan untuk melihat bagaimana hubunngan antar anggota keluarga, sering merupakan bagian dari sesi-sesi konseling keluarga. Perbuatan yang tampak adalah hasil interaktif anggota di dalam keluarga. Interpretasi atau penafsiran, tahap ketiga ini adalah bagian penting dalam konseling, tujuannya adalah untuk menimbulkan insight (pemahaman bagi anggota keluarga tentang apa yang telah dilakukan) dan mendorong mereka untuk menterjemahkan apa yang telah mereka pelajari dan diterapkan bagi perilakunya seharihari. Konselor memberikan saran untuk seorang anggota keluarga memberikan tafsiran perilaku terhadap anggota lain.

\section{Rational Emotif Therapy}

Tujuan rational emotif therapy dalam konseling keluarga pada dasarnya sama dengan yang berlaku dalam konseling individual atau kelompok. Anggota keluarga dibantu untuk melihat bahwa mereka bertanggung jawab dalam membuat gangguan bagi diri mereka sendiri melalui perilaku anggota lain secara serius. Mereka didorong untuk mempertimbangkan bagaimana akibat perilakunya, pikirannya, emosinya telah membuat orang lain dalam keluarga menirunya. Rational emotif terapi mengajarkan pada anggota keluarga untuk bertanggung jawab terhadap perbuatannya dan berusaha mengubah reaksinya terhadap situasi keluarga (Laela, 2015).

Ellis (1993) mengemukakan teknikteknik yang bersifat kognitif, emotif dan behavioral yang tepat untuk konseling keluarga. Teknik kognitif, teknik kognitif disesuaikan dalam kehidupan anggota keluarga dengan cara menggali secara luas gangguan emosi dan perilaku. Gangguan bukan disebabkan oleh kehadiran individu dalam situasi keluarga, tetapi oleh persepsi dan interpretasinya terhadap situasi keluarga sehingga menyebabkan ia terganggu emosinya. Ada individu yang menganggap bahwa tak sepantasnya orangtuanya miskin, karena orang tuanya tak mau bekerja keras sehingga menyebabkan keluarganya berantakan. Ide anak yang seperti ini menyebabkan ia terganggu emosionalnya sehingga berperilaku yang merugikan diri dan keluarganya, misalnya malas sekolah, merokok, dan lain sebagainya.

Teknik emotif, teknik ini didesain untuk menunjukkan kepada anggota keluarga bahwa 
perasaan mereka adalah hasil dari pemikiran mereka. Teknik evokatif dan dramatic adalah cara yang biasa dilakukan untuk mengubah filsafat dan keyakinan seseorang. Salah satu teknik yang dipakai perumpamaan, ibarat, tamsil dalam rational emotif yang digunakan untuk memadamkan atau menghentikan kebiasaankebiasaan yang tak diinginkan dan menggantikannya dengan kebiasaan baru yang diinginkan. Pada teknik ini klien disuruh menghayalkan perasaan-perasaan yang jelek (misalnya: kengerian, kemarahan, keputus asaan). Kemudian digantikan dengan perasaanperasaan tenang, sabar dan optimis.

Teknik Behavioral, teknik ini adalah bagian dasar dari rational-emotive terapi dalam konseling keluarga. Anggota keluarga diberi tugas-tugas pekerjaan rumah yang harus dikerjakan pada situasi nyata dalam keluarga dan bukan hanya dikhayalkan saja. Untuk menghindari keadaan keluarga yang tidak menyenangkan, maka orangtua mengusahakan agar anggota keluarga menghadapi situasi dan mencoba untuk mengubah cara-cara yang tidak sesuai. Penggunaan kontrak dengan konselor perlu untuk menjamin agar pekerjaan rumah dikerjakan oleh keluarga tersebut.

Selain itu, konseling keluarga dilakukan setelah masalah-masalah yang rawan pada diridiri anggota keluarga (bermasalah) telah dapat diselesaikan oleh konselor secara individual. Dengan cara demikian tugas konselor keluarga akan lebih ringan dalam membantu keluarga dalam menyelesaikan masalahnya dan menciptakan keluarga yang utuh, setelah lancarnya komunikasi diantara mereka melalui layanan konseling kelompok dengan pendekatan transaksional (Syahputra, Neviyarni, Netrawati, Karneli, \& Hariyani, 2019). Di dalam proses konseling keluarga, konselor berupaya sekuat tenaga agar setiap individu anggota keluarga yang terlibat dapat berbicara bebas menyatakan perasaan, pengalaman dan pemikiran tentang ayah, ibu juga saudara-saudaranya (Rahayu \& Rusminingsih, 2015; Shek \& Siu, 2019; Silvi, Hadi, \& Darmawati, 2018; Surendran, Venugopal, Dongre, \& Paninjukunnath, 2018; Vaish \& Ahmad, 2019).

Aziz \& El-Gazzar (2019) meninjau dari bidang kesehatan dengan memberi pelatihan kepada dokter dan perawat (hanya 36,7\% dokter yang merasa memiliki keterampilan komunikasi untuk memfasilitasi pengungkapan kekerasan dalam rumah tangga), sehingga di rumah sakit tersedia layanan kesehatan untuk mengidentifikasi dan mengelola korban kekerasan rumah tangga serta mendirikan sistem pendukung yang bertujuan untuk mengurangi konsekuensi negatif fisik dan mental dari paparan kekerasan rumah tangga.

Beberapa faktor penghambat pelatihan yang tidak memadai dari penyedia layanan kesehatan, yaitu: kurangnya kesadaran, kekurangan waktu, keengganan perempuan untuk mengungkapkan paparan mereka terhadap kekerasan dan persepsi kekerasan dalam rumah tangga sebagai masalah sosial yang terkait dengan penyedia layanan kesehatan (Amin, Buranosky, \& Chang, 2017; Beynon, Gutmanis, Tutty, Wathen, \& MacMillan, 2012; Zink, Regan, Goldenhar, Pabst, \& Rinto, 2004).

\section{Cognitive Behavioural Therapy}

Terapi perilaku kognitif menganggap bahwa kekerasan adalah perilaku yang dipelajari yang dapat dilupakan dan digantikan oleh perilaku non-kekerasan; Aldarondo, Etiony, \& Malhotra, 2014). Pelatihan ini berfokus pada keterampilan berkomunikasi, ketegasan, keterampilan sosial, dan teknik manajemen emosi yang merupakan pelatihan relaksasi, serta mengubah atribut negatif untuk mendorong kesadaran akan alternatif kekerasan (Babcock, Green, \& Robie, 2004). Keterampilan ini mendorong laki-laki untuk mengubah nilai-nilai, kepercayaan, dan tindakan mereka dengan berkonsentrasi pada pengetahuan mereka tentang hak-hak perempuan dan hubungan intim yang sehat dan saling menghormati.

Young (1999) terapi perilaku kognitif mengasumsikan bahwa klien termotivasi untuk berubah, tidak larut dengan masalah hubungan sebagai masalah utama, mampu mengubah kognisi dan pola perilaku, dan terampil terlibat dalam hubungan kolaboratif dengan seorang profesional selama beberapa sesi. Namun, banyak laki-laki kasar yang menolak untuk melakukan pengobatan (Lawson, Kellam, Quinn, \& Malnar, 2012). Oleh karena itu, pria yang memiliki representasi hubungan maladaptif harus menerima intervensi berdasarkan psikodinamik untuk mengatasi masalah yang terkait dengan keterikatan mereka.

Lebih lanjut, Prochaska \& DiClemente (1982) telah mendefinisikan tahap-tahap perubahan yang paling sukses dalam terapi perilaku kognitif sebagai: kontemplasi, landasan untuk perubahan, mengambil tindakan baru, dan pemeliharaan. Tahap-tahap ini membutuhkan 
keterlibatan dan janji peserta untuk mengubah perilaku kekerasan mereka.

Terapi perilaku kognitif menunjukkan tahap yang lebih tinggi dari tujuan perubahan seperti berfokus pada peningkatan keterampilan dan kesadaran perilaku kasar mereka daripada mendorong motivasi mereka untuk masuk ke dalam proses intervensi. Pendekatan pembelajaran sosial dan pendekatan manajemen emosi terbatas karena pria yang menggunakan kekerasan memaafkan perilaku untuk mendapatkan kekuasaan dalam rumah tangga (Harne \& Radford, 2008). Dapat dikatakan bahwa terapi perilaku kognitif gagal untuk menanggapi kebutuhan beberapa pelaku dalam proses mengambil tanggung jawab. Alasan untuk ini mungkin karena konsep patriarki, maskulinitas, kelas, hubungan kekuasaan gender dan kurangnya layanan yang sensitif secara budaya (Turhan, 2019).

\section{Feminist Therapy}

Terapi feminis mengasumsikan klien (pria/suami) harus mengatasi masalah inti seperti kurangnya nilai-nilai hubungan, pengungkapan diri/wawasan/empati, keterampilan komunikasi, keintiman, dan keterampilan dalam me-ngembangkan perilaku positif (Bograd, 2013). Program intervensi berbasis feminis ini bertujuan untuk meningkatkan kesadaran tentang peran seks dan peran emosi (Healey, Smith, \& O'Sulivan, 1999). Edley (2001) mengemukakan bahwa laki-laki kasar perlu terlebih dahulu mengakui bahwa perilaku mereka salah sebelum mereka dapat membuat pilihan untuk menjadi laki-laki yang tidak melakukan kekerasan dalam rumah tangga.

Untuk memahami identitas maskulin pria, konflik dan tujuan program berkaitan dengan kebutuhan peserta harus dipertimbangkan karena mereka mungkin tidak mau membagikan perasaan mereka selama sesi kelompok. Teori pendidikan feminis lebih cocok dengan pelaku yang menyadari konsekuensi dari perilaku kekerasan mereka daripada pendekatan psiko-terapi karena pendekatan feminis menekankan bahwa perilaku kekerasan adalah kriminal dan bukan hasil dari pengalaman masa lalu (Healey et al., 1999; Skinner, Hester, \& Malos, 2005). Kondisi ini yang membuat suami atau pelaku enggan untuk melakukan konseling (Syahputra et al., 2019).

Mengingat gagasan feminis yang kuat tentang pilihan pelaku laki-laki untuk melakukan kekerasan dan perlunya mereka untuk mau membuat pilihan sadar/berubah, teknik feminis adalah alat yang menjanjikan banyak pelaku yang bersedia untuk menemukan perilaku alternatif.

\section{SIMPULAN DAN SARAN}

Krisis keluarga dari tahun ke tahun terus meningkat, adapun krisis keluarga yang menjadi perhatian adalah masalah kekerasan dalam rumah tangga, kenapa demikian karena masalah keluarga sama seperti gunung es di tengah lautan. Artinya sedikit yang terlihat atau terekspos padahal banyak masalah yang belum terungkap, kondisi ini didasari oleh perasaan malu korban untuk melaporkan masalah keluarganya kepada orang lain sampai berakhir dengan kematian barulah tereskpos ke luar. Penyebab kekerasan dalam rumah tangga adalah sikap dan nilai yang salah tentang peran laki-laki dan perempuan, kekuasaan otoritatif dalam keluarga, ketidaksetaraan gender, status perempuan yang lebih rendah, dan kuasa atas perempuan, serta kepala keluarga yang mengelola atau mengendalikan perilaku semua keluarga yang biasa disebut dengan konsep patriarki. Berdasarkan pemaparan di atas, perlunya pelayanan bimbingan dan konseling untuk mengatasi perilaku kekerasan dalam rumah tangga. Selain itu, pelayanan bimbingan dan konseling dapat menggunakan empat pendekatan untuk mengatasi kekerasan dalam rumah tangga, yaitu: Adler therapy, rational emotif therapy, cognitive behavioural therapy, dan feminist therapy, serta ada tahapan menurut Adler dan teknik-teknik yang dikemukakan Ellis yang dapat digunakan konselor untuk membantu korban kekerasan dalam rumah tangga.

\section{DAFTAR RUJUKAN}

Aldarondo, Etiony, \& Malhotra, K. (2014). Domestic violence: what every multicultural clinician should know. In M. L. Miville \& A. D. Ferguson (Eds.), Handbook of Race-Ethnicity and Gender in Psychology (1st ed., pp. 379 -405). New York: Springer Science \& Business Media.

Alizamar, A., Syahputra, Y., Ardi, Z., \& Trizeta, L. (2018). Differences in aggressive behavior of male and female students using Rasch stacking. International Journal of Research in Counseling and Education, $3(1)$,

22-32. 
https://doi.org/10.24036/0051za0002

Amin, P., Buranosky, R., \& Chang, J. C. (2017). Physicians' perceived roles, as well as barriers, toward caring for women sex assault survivors. Women's Health Issues, 27(1), 43-49.

Andi Najemi, P. (2015). Ibm Kelompok PKK Desa Pematang Pulai dan Kel. Sengeti Tentang Hukum Gender Mengantisipasi KDRT. Jurnal Pengabdian Pada Masyarakat, 30, 41-57.

Aziz, M. M., \& El-Gazzar, A. F. (2019). Health care providers' perceptions and practices of screening for domestic violence in Upper Egypt. Sexual \& Reproductive Healthcare, 20, 93-99.

Babcock, J. C., Green, C. E., \& Robie, C. (2004). Does batterers' treatment work? A meta-analytic review of domestic violence treatment. Clinical Psychology Review, 23(8), $1023-1053$.

Beynon, C. E., Gutmanis, I. A., Tutty, L. M., Wathen, C. N., \& MacMillan, H. L. (2012). Why physicians and nurses ask (or don't) about partner violence: a qualitative analysis. BMC Public Health, 12(1), 473.

Bograd, M. L. (2013). Feminist approaches for men in family therapy (2nd ed.). New York: Routledge.

Dinkmeyer, D. C., Dinkmeyer Jr, D. C., \& Sperry, L. (1987). Adlerian counseling and psychotherapy. Merrill Publishing Co.

Edley, N. (2001). Analysing masculinity; interpretative repertoires, ideological dilemmas and subject positions. In $M$. Wetherell, S. Taylor, \& S. J. Yates (Eds.), Discourse as Data: A Guide for Analysis (p. 338). London: SAGE Publications.

Ellis, A. (1993). The rational-emotive therapy (RET) approach to marriage and family therapy. The Family Journal, 1(4), 292307.

Hariyani, H., \& Syahputra, Y. (2019). Whether there effect of the used video on group guidance services to aggressive behavior?.
Konselor, 8(3), 92-97.

Harne, L., \& Radford, J. (2008). Tackling domestic violence: Theories, policies and practice (First). Glasgow: McGraw -Hill International.

Healey, K., Smith, S., \& O’Sulivan, C. (1999). Batterer intervention: Program approaches \& criminal justice strategies. Washington, D.C: US Department of Justice Office of Justice Programmes, National Institute of Justice.

Jayanthi, evi tri. (2009). Faktor-faktor penyebab terjadinya kekerasan dalam rumahtangga pada survivor yang di tangani oleh lembaga sahabat perempuan magelang. Jurnal Dimensia, 3(2), 33-50.

Laeheem, K., \& Boonprakarn, K. (2017). Factors predicting domestic violence among Thai Muslimmarried couples in Pattani province. Kasetsart Journal of Social Sciences, 38(3), 352-358.

Laela, F. N. (2015). Bimbingan Konseling Keluarga dan Remaja. Surabaya: UIN Sunan Ampel Press.

Lawson, D. M., Kellam, M., Quinn, J., \& Malnar, S. G. (2012). Integrated cognitive - behavioral and psychodynamic psychotherapy for intimate partner violent men. Psychotherapy, 49(2), 190 -201.

Manan, M. 'Azzam. (2008). Kekerasan Dalam Rumah Tangga Dalam Perspektif Sosiologis. Jurnal Legislasi Indonesia, 5(3), 9-34.

Muttaqin, M. A., Murtadho, A., \& Umriana, A. (2016). Korban Kekerasan dalam Rumah Tangga di LRC-KJHAM Semarnag. Jurnal Sawwa, 11(April), 177-210.

Oktasari, M., Stevani, H., \& Siolihatun. (2018). Kajian Teoritis Layanan Konseling Untuk Korban Kekerasan dalam Rumah Tangga (KDRT). Jurnal Ilmu Pendidikan, Psikologi, Bimbingan \& Konseling, 3(1), 12-20.

Prochaska, J. O., \& DiClemente, C. C. (1982). Transtheoretical therapy: Toward a more 
42 | JURKAM: Jurnal Konseling Andi Matappa Vol 4, No 1, Februari 2020

integrative model of change. Psychotherapy, 19(3), 276-288.

Puawongpaet, S. (1994). Thai family: The problems and solutions. Journal of Public Welfare, 37(6), 20-24.

Rahayu, E. W., \& Rusminingsih, R. (2015). Pengaruh Konseling Keluarga Berencana terhadap Tingkat Pengetahuan dan Minat Menjadi Akseptor Keluarga Berencana Pasca Persalinan di Puskesmas Mlati II Yogyakarta. STIKES'Aisyiyah Yogyakarta.

Rahmawati, M. (2014). Menulis Ekspresif sebagau strategi mereduksi stres untuk anak-anak korban kekerasan dalam rumah tangga (KDRT). Jurbal Ilmiah Psikologi Terapan, 2(2), 276-293.

Shek, D. T. L., \& Siu, A. M. H. (2019). Adolescent Mental Health Policy and Services in Hong Kong: Seven Unresolved Problems Waiting for Solutions. Journal of Adolescent Health, 64(6), S5-S9.

Silvi, S., Hadi, M. F. Z., \& Darmawati, D. (2018). Pengaruh Konseling Pranikah Terhadap Keharmonisan Rumah Tangga Di Kua Desa Serapung Kecamatan Kuala Kampar Kabupaten Pelalawan. Al-Ittizaan: Jurnal Bimbingan Konseling Islam, 1(2).

Skinner, T., Hester, M., \& Malos, E. (2005). Researching gender violence: feminist methodology in action. Cullompton: Willan.

Straus, S. (2001). Contested meanings and conflicting imperatives: A conceptual analysis of genocide. Journal of Genocide Research, 3(3), 349-375.

Surendran, P., Venugopal, V., Dongre, A. R., \& Paninjukunnath, R. (2018). Perceived challenges faced by family caregivers of chronic kidney disease patients and suggested solutions: A qualitative study. International Journal of Medical Science and Public Health, 7(6), 487-493.

Sutrisminah, E. (2018). Dampak Kekerasan Pada Istri Dalam Rumah Tangga Terhadap Kesehatan Reproduksi. Majalah Ilmiah
Sultan Agung, 50(127), 23-34.

Syahputra, Y., Neviyarni, N., Netrawati, N., Karneli, Y., \& Hariyani, H. (2019). Analisis Transaksional dalam Setting Kelompok. Jurnal Bimbingan Dan Konseling AR-RAHMAN, 5(2), 123-130.

Syaodih, N. (2009). Metode Penelitian Pendidikan. Bandung: Remaja Rosdakarya.

Turhan, Z. (2019). Improving approaches in psychotherapy and domestic violence interventions for perpetrators from marginalized ethnic groups. Aggression and Violent Behavior, 101337.

Vaish, R., \& Ahmad, M. K. (2019). Common solutions to a finite family of inclusion problems and an infinite family of fixed point problems by a generalized viscosity implicit scheme including applications. Calcolo, 56(3), 29.

Young, J. E. (1999). Cognitive therapy for personality disorders: A schema -focused approach (3rd ed.). Sarasota, FL: Professional Resource Press.

Zink, T., Regan, S., Goldenhar, L., Pabst, S., \& Rinto, B. (2004). Intimate partner violence: what are physicians' perceptions? The Journal of the American Board of Family Practice, 17(3), 332-340. 